\title{
Strategies older New Zealanders use to participate in day-to-day occupations
}

\author{
Clare Hocking, ${ }^{1}$ Juanita Murphy ${ }^{2}$ and Kirk Reed ${ }^{3}$
}

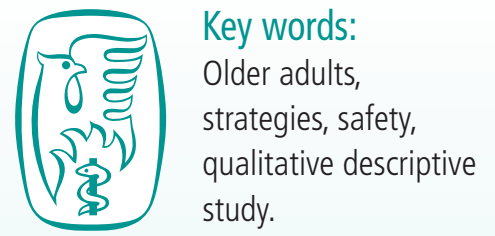

${ }^{1}$ Professor, Department of Occupational Science and Occupational Therapy, Division of Rehabilitation and Occupation Studies, Faculty of Health and Environmental Sciences, AUT University, Auckland, New Zealand.

${ }^{2}$ Occupational Therapist, Capital and Coast District Health Board, Wellington, New Zealand.

${ }^{3}$ Head, Department of Occupational Science and Occupational Therapy, Division of Rehabilitation and Occupation Studies, Faculty of Health and Environmental Sciences, AUT University, Auckland, New Zealand.

Corresponding author:

Dr Clare Hocking, Professor,

Department of Occupational Science and

Occupational Therapy, Division of

Rehabilitation and Occupation Studies, Faculty of Health and Environmental Sciences, AUT University, Private Bag 92 006,

Auckland 1142, New Zealand.

Email: clare.hocking@aut.ac.nz

Reference: Hocking C, Murphy J, Reed K (2011) Strategies older New Zealanders use to participate in day-to-day occupations. British Journal of Occupational Therapy, 74(11), 509-516.

DOI: 10.4276/030802211X13204135680820

(c) The College of Occupational Therapists Ltd. Submitted: 5 April 2010.

Accepted: 26 July 2011.
Aim: This exploratory study aimed to uncover the strategies that older adults employ to ameliorate the impact of impairments and barriers to participation.

Method: Eight participants were interviewed in their own homes, in a town or city in New Zealand.

Findings: Inductive analysis of data revealed four main categories of strategies: strategies to keep safe, to recruit and accept help, to meet social and biological needs (nutritional and medical), and to conserve financial, material and bodily resources.

Discussion: The study supports some previous findings of strategies used by older people, and demonstrates that enquiring into the strategies that older people devise and adopt into their own lives is a productive line of inquiry. The strategies described differ from those that occupational therapists recommend, and do not incorporate public health messages about the benefits of physical activity or recommendations about falls prevention.

Conclusion: The findings suggest that asking older clients about the strategies that they use will uncover valuable information for therapists giving advice or issuing equipment to help older adults to manage in the community.

\section{Introduction}

Research into the experience of living with impairment is beginning to uncover the strategies that people use to participate in everyday occupations. Understanding the strategies that people adopt or devise for themselves is important for occupational therapists, who recommend strategies based on their accumulated professional knowledge. This paper reports an exploratory qualitative study that addressed the question: 'What strategies do older New Zealanders use to participate in day-to-day occupations that they need or want to do?' Strategies here means those practical plans of action and ways of doing things that people put in place to make it easier to manage difficulties encountered or anticipated.

The study aimed to uncover the strategies that older adults employ to ameliorate the impact of impairments and barriers to participation, with an overall objective of supplementing occupational therapists' knowledge of ways to assist people to manage at home with information about the strategies that they implement on their own behalf. As such, the study is part of a general shift towards acknowledging the value of 'lay' knowledge - people's reports of their own experiences - as opposed to trusting only the 'expert' knowledge generated from health professionals' observations and measurements (Fairhurst 2005).

\section{Literature review}

Occupational therapists have a long history of assisting people to manage everyday occupations (Weaver 1956, Gordon et al 2009) by applying principles 
of energy conservation, work simplification, universal design and environmental modification (Crepeau et al 2008, Curtin et al 2010) and an expansive knowledge of assistive technologies (Cook and Polgar 2008). There is some indication in the literature, however, that therapists recognise that people also make their own plans to manage occupation (HäggblomKronlöf et al 2007), often taking personal and environmental factors, such as the weather, into account.

Some responses to functional restrictions and barriers to participation have been identified in a small number of relatively small-scale studies that addressed directly the practical strategies that older adults use. One study focused on the maintenance of independence and reported generalised strategies, such as staying physically active, budgeting carefully and eating healthy food, along with more specific actions, such as reducing the rate of performance or amount of activity (Yuen et al 2007). Studies of people with Alzheimer's disease have uncovered the various strategies that they use. Examples include keeping track of the time and date by making a small purchase to get a docket with today's date, and practising the use of household technologies, such as telephones, frequently (Nygård 2008). They also employ routines; environmental strategies, such as strategically locating objects; and cognitive strategies, including checking, allowing surplus time, taking things one at a time and doing things immediately (Nygård and Ohman 2002). Family members of people with Alzheimer's disease use similar strategies to support their participation, by putting things where they will be noticed, demonstrating how to do things and introducing activities that require repetitive movements, like sweeping (Gitlin et al 2002).

In addition to these broadly focused studies, some researchers have focused on specific aspects of daily living. For instance, older adults manage medications by establishing routines and reminders, using tools such as pliers to open medication bottles, and decanting pills into smaller containers to take with them when they go out (Bytheway 2001). Older Swedish women manage food shopping and cooking by purchasing ready-to-eat or instant products, and using familiar recipes. Additionally, the women with reduced strength manage heavy groceries by making frequent trips to purchase a few items, recruiting a family member, or using a bike, shopping trolley or pram to carry groceries (Sidenvall et al 2001). Equally, independent-living people with dementia manage telephone use by highlighting important numbers, keeping the phone in the same place, and repeating a number out loud (Nygård and Starkhammar 2003).

Studies of older people's experience of ageing in place, or living with a disability, have also uncovered a range of strategies. These include using carefully scripted routines and installing something to hang onto while negotiating outdoors steps (Heatwole Shank and Cutchin 2010), throwing, rather than carrying, laundry downstairs to the washing machine, and arranging the delivery of readymade meals (Tollén et al 2008). Strategies have also been identified by researchers investigating public health issues, such as the ways in which local environments affect older people's health. Day (2008), for example, noted that older people used benches in local shopping areas to socialise.

Taken as a whole, the literature shows that health professionals are beginning to record some of the strategies that older people come to without professional help. Although both qualitative and quantitative methods have been employed, the studies tended to be small scale and the strategies were sometimes uncovered inadvertently in studies focused on broader questions. Many of the strategies identified appear obvious, yet there is value in accumulating such knowledge so that older people's practical wisdom can be shared among them. This might create opportunities for less practically minded older people to learn from their peers, while alerting health professionals to the resourcefulness of many older clients and the kinds of strategy likely to be acceptable to them. The aim of this study was to supplement the existing knowledge by explicitly asking older adults about the strategies that they use to participate in their day-to-day occupations.

\section{Method}

To investigate the practical ways in which older people manage their occupations, a qualitative descriptive approach was taken, using individual interviews. This method explores human existence as it occurs in everyday life (Sandelowski 2000) and generates straightforward descriptions of 'a phenomenon of interest' (Marshall and Rossman 2006, p34). The findings are presented as a low-inference interpretation of information provided by the participants (Sandelowski 2000). Researchers assure the credibility of the findings by ensuring that the descriptions convey the events and meaning intended accurately (Patton 2002).

\section{Participants}

A convenience sample was recruited through a presentation to a friendship group at a local church where the second author had contacts, referral from community members who knew of the study, and snowballing from prospective participants (Patton 2002). The inclusion criteria specified being 65 or more years old, community dwelling and receiving or providing support with self-care or domestic tasks, which was taken as an indicator of needing, using and being able to discuss the strategies implemented to manage perceived challenges. Participants were also required to have conversational English language skills, to be cognitively able to provide informed consent and to recount their strategies, and not to be experiencing an acute health condition. Eight participants, one man and seven women, were recruited, seven of them from a major city in New Zealand and one from a provincial town. They ranged in age from early $70 \mathrm{~s}$ to 98 years and had diverse living situations, but did not represent the ethnic diversity of New Zealand's population in that all were Caucasian (see Table 1 for the demographic data). Recruitment ceased when redundancy of information was becoming apparent. 
Table 1. Summary of demographic data of the participants

\begin{tabular}{lccl}
\hline Participant & Age & Gender & Living situation \\
\hline 1 & $80-84$ & Male & With spouse, in unit, spouse with dementia \\
2 & $75-79$ & Female & Alone, in unit \\
3 & $80-84$ & Female & Alone, in unit \\
4 & $80-84$ & Female & Alone, in house for 40 years, spouse in \\
& & & rest home \\
5 & $70-74$ & Female & With spouse, in town house, spouse \\
6 & 98 & Female & With daughter, in house for 60 years \\
7 & $70-74$ & Female & With spouse, in unit, spouse with dementia \\
8 & $85+$ & Female & Alone, in house several years \\
\hline
\end{tabular}

\section{Ethics}

The Auckland University of Technology Ethics Committee approved the study (Ref no. 06/201). Risks to participants were mitigated by recruitment through a public event or through a third party, by inviting participants to have a support person present during data collection, and by removing or disguising identifying information. All participants gave written consent to participate. Researcher safety was addressed by ensuring that someone had knowledge of the date, time and place of the interviews.

\section{Data collection}

Semi-structured interviews, 45 to 90 minutes in duration, were conducted by the second author in the participants' homes, which allowed them to demonstrate any equipment associated with some of the strategies discussed. The interviews were audio-taped and transcribed. Questions asked about how participants were affected by their impairments. The participants were then invited to 'Tell me how your impairment affects your ability to do' the occupations that they had identified, 'What is different about how [the activity] is done now?' and whether they 'use another person to assist in any tasks?' The focus was on the changes made to the way in which things were done and how they came to that method. Categories, such as looking after themselves or what they do for leisure, were used to open up new strands of conversation.

\section{Data analysis}

The main tasks of analysis are data reduction, data display and drawing conclusions (Miles and Huberman 1994). A general inductive approach was selected to find the core meanings relevant to the research objectives, and to outline and describe categories of information (Thomas 2006). Following the process outlined by Thomas (2006), familiarity with the data was established by listening to the audio files and reading the transcripts several times, with ongoing data collection and analysis occurring simultaneously. Analysis involved printing transcripts on different coloured paper. Categories, derived from actual phrases or meanings conveyed in the text, were identified, and transcripts literally cut up into piles for further consideration. Overall names of categories emerged over time and in discussion between the three authors, following which excerpts from the electronic files were organised under headings in an Excel spreadsheet for easier management.

Categories were added as new strategies were identified, and data were reorganised as new sense was made of existing categories. For example, all of the strategies involving money were initially grouped in a category labelled financial strategies, but were later reallocated to categories and subcategories, such as meeting biological needs and conserving resources. It also became clear that strategies did not exist in isolation; for example, strategies to conserve resources had an impact on strategies for getting food and maintaining social contacts. Several segments of text could have been assigned to more than one category, and were ultimately grouped into the category with which they had the strongest association. Unassigned data were reviewed and found to be unrelated to the study objectives. Once the process of refinement of the categories was complete, they were assigned a final label and short descriptions of the category were written. A number of categories contained counter examples, such as the participant who described taking a risk that was outside her usual safety practices.

\section{Rigour in data collection and analysis}

The credibility of the findings was enhanced by empathically listening to participants' accounts and, at the end of each interview, summarising the information conveyed and asking if there was anything they wished to add, correct or challenge (Thomas 2006). In addition, the transcripts were carefully checked against the audio files; interpretations were challenged in regular meetings of the co-authors, thus providing a form of peer review; and notes about the development of the categories were kept as an audit trail (Krefting 1991). A copy of the overall findings was posted to the participants. One had passed away, and five of the remaining seven responded, affirming the strategies outlined and offering additional strategies to keep safe. Inclusion of the participants' words alongside the researchers' interpretations allows readers to view the data coded against each category, and provides a thick description of the findings (Sandelowski 2000).

\section{Findings}

The analysis generated four categories: strategies to keep me safe, to recruit and accept help, to meet social and biological needs, and to conserve resources. Each category is illustrated with participant quotes. Although interrelated, the categories are presented separately for clarity.

\section{Category 1: Strategies to keep me safe}

This category captures the things that participants put in place to give a sense of physical and psychological safety. It is presented first because safety concerns underlie the strategies reported in other categories. One strategy to manage risks was to relocate to a safer environment, such as a smaller, more manageable home or to a property in a flatter area: 
We had to move because we were living up the hill ... This house is actually a very suitable home. Everything is sort of easy to get to, and where the bathroom is and the wide passage because he was already in a wheelchair then.

Other reasons to relocate were to escape unruly neighbours and proximity to medical facilities, because 'sometimes I have to go to the hospital from the doctors'. Not moving was also a strategy, for instance if deteriorating vision made it safer to remain in a familiar environment. Moving did not always work out as planned, however, with one participant finding that the increased safety of being closer to his son did not compensate for the lack of social connections.

Another strategy was to alter the physical environment to reduce the risk of falls. Most participants had some form of equipment, ranging from a walking stick purchased at the pharmacy to hoists and shower chairs. The most common modification was rails to hold while getting in and out of the shower, or descending steps. Although rails were readily accepted other equipment was not, such as the 'hospital seat' that 'some nurse came and put' in the bath:

I haven't been using it; ... I'll have to stop getting right down in the bath now but I like to get properly clean and you feel better getting right in the water don't you.

Being safe also meant modifying the way in which they approached tasks or reassessing occupational choices to reduce risk. After a couple of falls, one participant was 'very careful in case I slip ... so you know I take my time with everything I do'. Another used a walking frame when outdoors, or leaned on the supermarket trolley. Being safe also meant choosing not to do things that they had previously enjoyed, such as gardening, because 'it's not worth the risk'. To access help, some participants had a personal alarm and a few had considered calling on neighbours, particularly if someone had 'taken the trouble' to reassure them of their willingness to help. Being assertive about who could enter their home and occasionally taking risks were also reported, such as the participant who accepted a lift from a stranger when she ran out of breath on the way home from shopping.

\section{Category 2: Strategies to recruit and accept help}

This category is about how the participants recruit and accept the assistance they need with everyday tasks. Help came from different sources: formal help from agencies or institutions such as hospitals or home care agencies, informal help from family and friends or neighbours. Help was either casual or structured, in that it was regular and organised. Requesting assistance directly occurred most often when someone living in the same household was able and willing to assist. For instance, one participant who had difficulty hanging out the washing found that her husband 'can hang it out [and] he will bring it in. He will fold it. He's a very good folder. Better than me actually' More immediate help with personal care required knowing that the person was close by, not 'wandering down to the letterbox'. Help might be recruited just in case they lost balance or were unable to get up, and might involve quite complex strategies:

The hospital lent us a bath chair that swivels around. You sit in it to have a shower over the bath, but we haven't got a shower so we had to use a dipper. But then that got [to be] a problem because of the arthritic leg, getting over the bath. What we've done is, I use a big bucket to wash the feet and legs first, then we do the rest of the body sitting on the chair over the bath.

Participants also recruited help from people outside their home, which involved notifying agencies when their circumstances changed to modify the help already in place:

We used to send the laundry to the IHC every Tuesday morning ... but they've closed. So they've [health care agency] allowed the lady that does the cleaning [an extra] 20 minutes, once a week.

Help might be recruited by discussing concerns with someone, and getting that person to search for information and action solutions. Being seen to require help is another method, as is picking up on other people's initiatives; for example, going to find out about council flats when a friend mentioned she was going.

Recruiting help appears complex. Some participants seemed quite skilled at recruiting help in a variety of ways, and others were very selective. Some recruited friends and family positively, and others because they needed to, for instance, get 'backwards and forward to the hospital'. Recruiting help might mean accepting that someone else would pay for the assistance received, or arranging to exchange one service for another: 'another couple who have their car in our garage bring the mail and paper down'. The use of familiar and repeated strategies was evident, but some participants actively determined the limits of the assistance they would accept. Recruiting assistance might also be problematic, if the people they relied on were intrusive in other ways or if they had little control over the situation.

In addition to strategies to recruit help, the participants had developed strategies for accepting and managing the help they needed. Most remained involved in the activities they required assistance with: they worked actively with the helper, doing as much as they could and accepting help for the rest. Others accepted the help, but on their own terms, resisting being bossed about by those who assisted them and expecting helpers to align their methods with the participants' habits and household routines, such as what is to be cleaned and how often: "She said to me, "Have you been doing the dusting?" And I said, "No, I'm not into dusting!"

Accepting help sometimes meant acknowledging that tasks would not otherwise be possible, such as 'our lady who does the showering':

By the time I've had a shower and got dressed again, I've absolutely had it. It sort of knocks the hell out of me. But it does help, you know, I feel far better for it. It's good. I wouldn't have a shower if she wasn't coming ... 
Accepting help might also include concerns about the number of jobs home helpers are expected to do within a limited timeframe, and whether that was fair. Participants indicated their acceptance by doing what the helper directed, by having a friendly relationship with the helper and by evaluating the helper's work positively, but varied in the extent to which accepting help was a part of everyday life. For instance, some had integrated the help into their day:

I'm the breakfast cook, I do all that, and the lady does the showering. Um, cleans the shower, does the lunches. Then I do the evening meal.

Other participants saw the formal assistance they received as useful but kept it distinct from the rest of the day or week, appearing less keen for the involvement to intrude on their routine and minimising the intrusion by decreasing the jobs.

Another approach to accepting help was to assess its veracity or motivation, checking whether offers of assistance were genuine and the reasons that the help was offered. Participants were more likely to accept help with tasks perceived as essential, such as shopping for food and medical matters, or if the assistance was only needed for a short time. The impact of accepting help, however willing, might be such that a task was taken back. For instance, one participant resumed the weekly shop because it provided him with an outing and some social interaction.

\section{Category 3: Strategies to meet social and biological needs}

These are the strategies that participants used to gather and prepare food, have social contact and fulfil their roles and obligations. Food was acquired in a variety of ways, from walking to get the groceries themselves to arranging others to purchase on their behalf:

I've got bags that I can sit in there [on the seat of the walking frame] and I've got an old belt that stops them from falling off ... I can't do it all in one trip. I have to go down twice and sometimes I go down just for the walk and company.

Other strategies, such as bringing groceries home in a taxi, were put in place because 'it was just too much and I thought, "Well you've got to be sensible". Contingencies, such as bad weather, required having more than one strategy, and might involve a combination of strategies. A heavy shopping trolley, for instance, might require asking a bus driver to assist and dragging it 'up the footpath backwards, very, very slowly'. Carefully timing shopping trips and other household tasks was another strategy; 'I can easily pop around to the supermarket ... when he's been showered in the morning, at least 'til 12 or 1 o'clock he's asleep'. For those reliant on others to do the shopping, meal delivery services were an option. Another, perhaps more risky, strategy was to:

... give the home helper a blank cheque ... as far as I know we're not allowed to give these people money. I usually write New World on it. The lady at the checkout said I didn't need to do that because the cash register prints out the name [of the shop] as well. So luckily it has the [shop] name endorsed on it twice.
Participants also had strategies to make food preparation easier:

We buy those things from the supermarket, you know, cottage pies that sort of thing. And with vegetables we use those 'Watties, in the bag'. There's no peeling, no waste you know.

Other ways to address declining strength and stamina included putting butter to 'soften in the sun' and cooking a pumpkin intact before scooping out the softened flesh. Other energy saving strategies were 'to put things where they're easy to reach'; for instance, leaving 'all the pots on the stove'.

Strategies for getting out were equally varied, and some required considerable resourcefulness. Social clubs and other long-standing social activities might 'send a car up for me and they bring me home in the car'. Outings with family could involve going for a drive, using a walking stick and taking someone's arm, or for longer distances and accessible venues, purchasing or arranging the loan of a wheelchair: 'I get in it at the church and they wheel me in and I stay in it all the time I'm in there.' Those less able to get out were reliant on regular visitors, or carrying their cordless phone with them in the house, sometimes in a bag attached to their walking frame.

\section{Category 4: Strategies to conserve resources}

These are strategies to conserve financial resources, physical capacity (such as breathing and energy) and their body (such as their senses, vision and hearing). Some strategies involved cutting back, for example 'doing away' with pay television or choosing low cost activities, like reading books that had been accumulated earlier in life. Cutting back also commonly involved reducing the number of clubs they attended and the frequency of attendance, and cutting back on electricity use. The latter involved drying washing in the bathroom with a window open rather than by the heater, and reducing household heating. One participant reported putting the heater away: 'I just sit here and I've got a blanket I throw over me'. Another described how she:

... was in bed most of the time. I had the heater on in the hall at night. I shut the doors and leave my bedroom door open. It isn't very hot, it takes the chill [off], and I think that's the main thing.

Strategies to conserve resources frequently concerned transport arrangements. Since many of the participants could not physically manage bus travel they had accessed taxi vouchers, but only used them to bring the groceries home or to go to the hospital. Complex arrangements to share taxi fares were also in place. Rationing the use of their resources included carefully selecting programmes if glaucoma made watching television difficult. Fatigue was a common issue and participants requested or accepted help, as discussed earlier, and conserved energy, for example by cleaning their houses by doing 'two rooms and the next day I'd do the other two. That was my routine'. The use of energy conservation strategies might be determined by fluctuating health status: 
Some days you're really short of breath, you can't sort of walk out the door, and go to the letterbox down there, maybe three stops. Another day, you can walk down there and you wouldn't think there was anything wrong. It is best that we know what we're capable of ... Better to try and pace yourself if you possibly can.

Knowing their capacity might mean implementing what was taught in 'respiratory classes at the hospital' where 'you learn, to control your breathing and not to panic so much, because there's nothing more frightening than being short of breath and wondering if you're going to make the next breath'. Part of conserving resources was to hold something in reserve, and to that end some participants had built up stocks of the things that they thought they would need in old age, such as clothing. In general, conserving resources demanded that participants were aware of the cost of goods and services, could find cheaper options and made do with resources they had.

Overall strategies were adopting an attitude of 'just getting on with it'. They did not perceive themselves as doing anything special, rather that they were using common sense to manage their lives. They voiced this as assertions that 'there are always solutions to every problem, just exercise your lateral thinking' and 'what are you to do... you get on with it'. Having a sense of humour, although not articulated by the participants, was also a strategy many used to overcome otherwise overwhelming situations. Relating a situation where her husband had fallen, one participant described phoning for an ambulance and saying:

Well I'm going to put the eiderdown on you and give you a pillow, just stay there. And we both started laughing because I said 'Well I can't get you up!'

\section{Discussion}

In seeking to access the insights accumulated by people with disabilities and impairments, this study goes part way to addressing the charge that the knowledge that professionals 'produce does not accurately portray the actual experience of the persons they call their patients or clients' (Thibodaux 2005, p508). The findings reveal that the participants had some well defined strategies to manage the activities occupational therapists are typically concerned with, such as showering and other self-care activities. However, the strategies that the participants shared predominantly related to safety, shopping and getting around. That may have been because the participants were less willing to discuss aspects of self-care with someone they did not know well, but the second author's extensive experience as a community occupational therapist indicates that this would not usually be the case.

There is some alignment between the findings of this study and other reports of the strategies that older people action. For instance, the 'economical thinking related to money and their own work' that Sidenvall et al (2001, p166) identified in relation to older Swedish women's management of food shopping and cooking aligns with the broader strategy of conserving resources identified here. However, none of the environmental strategies used to manage medications (Bytheway 2001), or the strategies employed by people with Alzheimer's disease to orient themselves to the time and date, and to use the telephone (Nygard and Öhman 2002, Nygård and Starkhammar 2003, Nygård 2008), were reported by participants in this study. Nevertheless, like Tollén et al (2008) and Heatwole Shank and Cutchin (2009), the present authors did uncover some highly situated strategies, such as dragging a shopping trolley, backwards, up the path to the house.

It is notable that where the professional literature that addresses the safety of older adults has concentrated on housing, specifically the person-environment fit (Iwarsson 2005) and fall prevention (Nyman and Ballinger 2008), the participants' safety concerns encompassed people and how they carry out the daily occupations associated with hygiene and survival. Consistent with Wilcock's (1993) theory of the human need for occupation, they took action to reduce the personal limitations and environmental barriers that interrupted those vital relationships and activities. The impetus for the particular strategies they developed or adopted seems to align with Wilcock's proposal that experiencing problems or discomforts, such as feeling unsteady going up and down steps, hunger, shortness of breath or feeling tired or lonely, stimulates a response. Alternatively, the participants may have been driven by the need for a sense of purpose, satisfaction, fulfilment and pleasure that Wilcock proposed. However, none of the strategies that were identified aligned with Wilcock's suggestion that people experience an 'energy surge to use capacities' (p19).

In addition, although the participants identified modifications to their homes, none offered strategies to remove tripping hazards such as floor rugs. Whether that was because it had not occurred to them, or because the objects in their homes serve other functions that are deemed important, is not clear. Also at variance to the professional literature, the participants did not identify strategies to increase strength, fitness or stamina, despite media messages promoting increased levels of physical activity that target all sectors of the population and evidence that programmes for older adults are effective (Fahlman et al 2007). Rather, the participants chose to avoid the risks associated with the way in which they performed their daily occupations (how much, how fast and how carefully), made different occupational choices, including withdrawing from various occupations, or accepted the need to have someone to assist them. The lack of response to public health messages about physical fitness and strength reinforces Wilcock's (2006) assertion that knowledge of the relationship between occupation and health needs to be disseminated to the public at large, perhaps at an earlier stage in life so that the importance of maintaining a range of occupations to support wellbeing is well entrenched before old age. 
It is also notable that, with the exception of energy conservation principles, there is not a clear alignment between the strategies that occupational therapists bring to practice with older people living in the community and the categories of strategies identified in this study. Rather than naming the technique, as in work simplification or environmental modification, the categories identified in this study point to the motives behind the strategy and the purpose it serves. This suggests that, informed by this study, occupational therapists in New Zealand, and perhaps other places, might consider asking older, independent-living clients what they do to keep safe, to get people to help them, to access food and company, and to conserve their resources. As suggested earlier, knowledge of the strategies that clients implement independently would provide a context against which strategies derived from occupational therapy theory might be considered.

Finally, some of the participants in this study appeared to have multiple strategies, while others reported only a few. That difference might simply mean that some participants faced more challenges, thus requiring more strategies, or had built up a repertoire of strategies over a longer time. Given the possibility that having a range of strategies might be advantageous, and in light of the finding by Lang et al (2002) that older people who are resource-rich are better equipped to adapt to the losses associated with ageing, further research to explore whether there is any advantage to being 'strategy rich' might be fruitful. It was also not clear how the participants came to the strategies they implemented, although it seemed that some were derived from trial and error and others were opportunistic, suggested by or copied from someone else. There did seem to be interest in hearing about the strategies used by other participants, and that prompted participants to recall further strategies of their own.

\section{Strengths and limitations}

The occupational focus, the second author's extensive experience of working in the community and the initial assumption that older New Zealanders are resourceful in addressing the practical problems of everyday living were strengths of the study.

The study has a number of limitations arising from the small sample size and the convenience sampling method. The participants were relatively culturally homogeneous, and resided in two urban settings with similar climates and terrain. It is likely that older people from other cultural backgrounds and those living in inner-city apartments, in hotter or colder climates, or in different family or living contexts might need and deploy quite different strategies to counter different weather conditions and to manage different features of the built environment. In addition, data were gathered through interviewing; it is likely that this obscured taken for granted accommodations, such as resting a walking stick against a window sill to prevent it falling out of reach. Observational strategies would add other layers of information. Another key limitation is that the study was not longitudinal, which means that it has not generated insights into the ways in which strategies are devised, adopted and modified over time.

\section{Conclusion}

A group of older people who were resident in a city or town in New Zealand and who had support with everyday activities were found to use four types of strategies to manage their participation in self-care, domestic and community occupations. Those strategies were to keep themselves safe, to recruit the help they need and ensure it is acceptable to them, to meet their biological and social needs, and to conserve their resources. The findings suggest that seeking information about the strategies that older people use to manage their everyday lives is a productive line of inquiry that may generate new insights for occupational therapists. Specifically, knowledge of the strategies older people independently deploy gives an insight into the ways in which older people think about managing the challenges they encounter and how to address those challenges.

In categorising the findings using language reflective of the participants' self-report, the findings might also suggest how therapists ought to frame questions to uncover the strategies that clients have adopted into their own lives. Further research to uncover the strategies employed by older adults living in other circumstances, research designs incorporating an observational component, and longitudinal studies to investigate the process of devising and adopting strategies are recommended.

\section{Acknowledgements}

Our sincere thanks to the participants in the study, who generously shared aspects of their personal lives, and endorsed the initial findings of the study. Conflict of interest: None declared.

\section{Key findings}

- Occupational therapists need to ask older people about their strategies to manage everyday occupations.

- Older people's strategies focus on safety, being helped, meeting needs and managing their resources.

\section{What the study has added}

The types of strategy that older people use are described. Like the professional literature, the strategies focus on safety, but with more emphasis on people and resources, and less on self-care. Longitudinal research of the process of adopting strategies is recommended.

\section{References}

Bytheway B (2001) Responsibilities and routines: how people manage their long-term medication. Journal of Occupational Science, 8(3), 5-13.

Cook AM, Polgar JM (2008) Cook and Hussey's assistive technologies: principles and practice. 3rd ed. St Louis, MO: Mosby Elsevier.

Crepeau EB, Cohn ES, Boyt Schell BA, eds (2008) Willard and Spackman's occupational therapy. 11th ed. Philadelphia: Wolters Kluwer/Lippincott Williams and Wilkins. 
Curtin M, Molineux M, Supyk-Mellson J, eds (2010) Occupational therapy and physical dysfunction: enabling occupation. 6th ed. Edinburgh: Churchill Livingstone.

Day R (2008) Local environments and older people's health: dimensions from a comparative qualitative study in Scotland. Health and Place, 14(2), 299-312.

Fahlman MM, Topp R, McNevin N, Morgan AL, Boardley DJ (2007) Structured exercise in older adults with limited functional ability. Journal of Gerontological Nursing, 33(6), 32-39.

Fairhurst E (2005) Theorizing growing and being older: connecting physical health, well-being and public health. Critical Public Health, 15(1), 27-38.

Gitlin LN, Winter L, Dennis MP, Corcoran M, Schinfeld S, Hauck WW (2002) Strategies used by families to simplify tasks for individuals with Alzheimer's disease and related disorders: psychometric analysis of the Task Management Strategy Index (TMSI). The Gerontologist, 42(1), 61-69.

Gordon B, Riordan S, Scaletti R, Creighton N, eds (2009) Legacy of occupation: stories of occupational therapy in New Zealand 1940-1972. Auckland: Bush Press.

Häggblom-Kronlöf G, Hultberg J, Eriksson BG, Sonn U (2007) Experiences of daily life at 99 years of age. Scandinavian Journal of Occupational Therapy, 14(3), 192-200.

Heatwole Shank K, Cutchin MP (2010) Transactional occupations of older women aging-in-place: negotiating change and meaning. Journal of Occupational Science, 17(1), 3-12.

Iwarsson S (2005) A long-term perspective on person-environment fit and ADL dependence among older Swedish adults. The Gerontologist, 45(3), 327-36.

Krefting L (1991) Rigor in qualitative research: the assessment of trustworthiness. American Journal of Occupational Therapy, 45(3), 214-22.

Lang F, Rieckmann N, Baltes M (2002) Adapting to aging losses: do resources facilitate strategies of selection, compensation, and optimization in everyday functioning? Journal of Gerentology, 57B(6), 501-09.

Marshall C, Rossman G (2006) Designing qualitative research. 4th ed. Thousand Oaks, CA: Sage.
Miles MB, Huberman AM (1994) Data management and analysis methods. In: NK Denzin, YS Lincoln, eds. Handbook of qualitative research. Thousand Oaks, CA: Sage, 428-44.

Nygård L (2008) The meaning of everyday technology as experienced by people with dementia who live alone. Dementia, 7(4), 481-502.

Nygård L, Öhman A (2002) Managing changes in everyday occupations: the experience of persons with Alzheimer's disease. OTJR: Occupation, Participation and Health, 22(2), 70-81.

Nygård L, Starkhammar S (2003) Telephone use among noninstitutionalized persons with dementia living alone: mapping the difficulties and response strategies. Scandinavian Journal of Caring Sciences, 17(3), 239-49.

Nyman SR, Ballinger C (2008) A review to explore how allied health professionals can improve uptake of and adherence to falls prevention interventions. British Journal of Occupational Therapy, 71(4), 141-45.

Patton MQ (2002) Qualitative research and evaluation methods. 3rd ed. Thousand Oaks, CA: Sage.

Sandelowski M (2000) Whatever happened to qualitative description? Research in Nursing and Health, 23(4), 334-40.

Sidenvall B, Nydahl M, Fjellstrom C (2001) Managing food shopping and cooking: the experiences of older Swedish women. Ageing and Society, 21(2), 151-68.

Thibodaux LR (2005) Habitus and the embodiment of disability through lifestyle. American Journal of Occupational Therapy, 59(5), 507-15.

Thomas DR (2006) A general inductive approach for analyzing qualitative evaluation data. American Journal of Evaluation, 27(2), 237-46.

Tollén A, Fredriksson C, Kamwendo K (2008) Elderly persons with disabilities in Sweden: their experiences of everyday life. Occupational Therapy International, 15(3), 133-49.

Weaver JH (1956) Some aspects of domiciliary occupational therapy with the physically handicapped. Occupational Therapy, 19(4), 120-24.

Wilcock AA (1993) A theory of the human need for occupation. Journal of Occupational Science: Australia, 1(1), 17-24.

Wilcock AA (2006) An occupational perspective of health. 2nd ed. Thorofare, NJ: Slack.

Yuen HK, Gibson RW, Yau MK, Mitcham MD (2007) Actions and personal attributes of community-dwelling older adults to maintain independence. Physical and Occupational Therapy in Geriatrics, 25(3), 35-53. 